\title{
Number of Biological Sisters
}

National Cancer Institute

\section{Source}

National Cancer Institute. Number of Biological Sisters. NCI Thesaurus. Code C135501.

The number of sisters that are biologically related to the subject. 